ARTículos 



\section{LA ARGUMENTACIÓN SILOGÍSTICA: UNA DEFENSA MATIZADA *}

Neil MacCormick

Universidad de Edimburgo

RESUMEN. Este trabajo defiende el papel central del silogismo como estructura del razonamiento jurídico, sin negar la relevancia del razonamiento informal, probabilístico o retórico. En la justificación hay que invocar los enunciados jurídicos universales relevantes (premisas mayores), y los hechos particulares relevantes a la luz de ellos (premisas menores) como ejemplificaciones de esos universales, siendo la pretensión o decisión la conclusión del silogismo. Por supuesto que pueden surgir problemas: de interpretación de la ley, de prueba de los hechos, de calificación de estos como casos particulares del supuesto de la norma (o de su valoración cuando esta incluye estándares valorativos), o de relevancia de la norma (si aplicamos jurisprudencia). Todo ello requiere dar razones a favor de una determinada lectura del silogismo, razones que van más allá de la lógica formal y acaban siendo las decisivas. Pero «el silogismo es lo que proporciona el marco dentro del cual esos otros argumentos cobran sentido como argumentos jurídicos».

Palabras clave: argumentación jurídica, silogismo, lógica, interpretación, prueba, calificación jurídica, norma jurídica.

ABSTRACT. This paper defends the central role of syllogism as the structure of legal reasoning, whithout denying the important part played by informal, probabilistic or rhetorical reasoning. To justify, one needs to cite universal legal sentences (major premises), and the particular facts which are relevant to them (minor premises), the claim or decision being the conclusion of the syllogism. To be sure, problems may arise: problems of interpretation of the statute; of proof of the facts; of classification of facts as instances of the universals deployed in the statute (as well as problems of evaluation of facts when the statute contains a value-expression); or problems of relevancy of the norm (when applying precedents). All that requires giving reasons for reading the syllogism in a certain way, a reasoning that falls beyond formal logic and ends up to be decisive. But syllogism «is what provide the framework in which the other arguments make sense as legal arguments».

Keywords: legal reasoning, syllogism, logic, interpretation, proof, legal classification, legal norm.

" Conferencia inaugural de la IV a edición del Curso de Especialista Universitario en Argumentación Jurídica, Universidad de Alicante, 21 de mayo de 2007. 


\section{INTRODUCCIÓN}

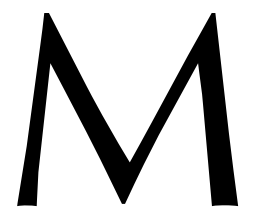

uchos autores se sienten incómodos, incluso hostiles, ante la idea de que la argumentación jurídica pueda ser deductiva. El problema es que el Derecho es normativo, y que el razonamiento sobre normas no puede ser estrictamente lógico. Yo no comparto esta idea, y en esta conferencia expondré algunas razones para discrepar de ella. Empezaré ofreciendo una fórmula esquemática simplificada para representar una norma o regla jurídica.

Lo que hacen las normas jurídicas es seleccionar algunos hechos —acciones o sucesos- posibles del mundo, y estipular que ciertas consecuencias normativas han de ligarse a ellos en Derecho. Los hechos seleccionados en una regla pueden verse pues como «hechos operativos», porque cuando suceden operan en el Derecho para justificar que en el caso dado se derive la consecuencia normativa dada. Así pues, en una representación esquemática, una regla es: «Siempre que sucedan los hechos operativos $O F$, la consecuencia normativa $N C$ ha de seguirse en relación con esos hechos». De modo más simple aún, puede representarse como: «Siempre que OF, entonces $N C$ ».

Desde esta descripción, parece que la aplicación del Derecho ha de ser un proceso intelectualmente simple. Ante cualquier caso, todo lo que hay que hacer es establecer que la situación fáctica $O F$ se ha producido, y que por tanto ha de seguirse $N C$. Esto no es más que el «silogismo hipotético» de los lógicos tradicionales.

$$
\text { «Si } O F \text {, entonces } N C
$$

OF

luego NC».

En este trabajo desplegaré argumentos para sostener que razonar de esta forma (que será desarrollada de un modo algo más elaborado) es verdaderamente central para el razonamiento jurídico. Lo cual equivale a retomar una pregunta muy antigua y darle una respuesta muy pasada de moda, quizás insultantemente arcaica. La pregunta: «¿Es el razonamiento jurídico, en algún sentido interesante, silogístico?». La respuesta: «Sí»; al menos «sí, con reservas y matices».

John DEWEY, sin embargo, propuso en su día que los juristas deberían abandonar vetustos pero engañosos formalismos y dedicarse a lo que él llamó «una lógica de predicción de probabilidades, más que de deducción de certezas» ${ }^{1}$. El artículo de DEWEY es uno de los grandes textos fundacionales del realismo jurídico norteamericano. Yo le sigo en cuanto a pensar que la certeza que podemos alcanzar en el Derecho es, como mucho, certeza limitada y derrotable. Tal vez era eso precisamente lo que él tenía en mente. Seguro que eso era al menos una parte, de lo que él tenía en mente. Sea como fuere, que la lógica y el formalismo no tenían cabida en el Derecho se convirtió en un tema dominante en la teoría del Derecho norteamericana a lo largo del siglo XX. DEWEY fue uno de los autores cuyas palabras se citaron a menudo para reforzar esa tesis; Oliver Wendell Holmes, Jr. fue otro, y Karl LlEwELlyn un tercero. Con un trío de se-

\footnotetext{
${ }^{1}$ Véase DeweY, 1924-25: «Logical Method and Law», Cornell Law Quarterly 10, 17, en p. 26.
} 
mejantes genios, quizá se ponga muy cuesta arriba la tarea de proponer cualquier otra visión con la esperanza de ser escuchado.

Con todo, hay bases sólidas para una visión diferente, como la que aquí se defenderá. Lo que hay que entender es que el silogismo juega un papel fundamental como estructura en el pensamiento jurídico, aunque no todo ese pensamiento se agota en su estructura únicamente. La lógica formal y la deducción sí que importan en el Derecho. Ciertamente, reconocer esto no exige negar el papel extraordinariamente importante que en el Derecho desempeñan el razonamiento informal, el razonamiento probabilístico, la retórica, en todos sus sentidos y modos. Antes al contrario: lejos de requerir la negación de todo eso, apreciar el lugar central del silogismo jurídico es precisamente una condición para entenderlo en su contexto jurídico ${ }^{2}$.

\section{EL SILOGISMO JURÍDICO}

Es evidente que en todos los sistemas jurídicos debe existir un principio muy general de Derecho procesal según el cual ningún alegante puede basarse en una ley escrita [statute] si no declara qué ley está invocando y cita sus partes relevantes. Para iniciar actuaciones sobre algún asunto jurídico, uno ha de identificar y citar las leyes en las que sustenta su postura. Este principio funciona en todos los sistemas que yo en algo conoz$\mathrm{co}^{3}$, y en realidad tendría que existir en cualquier sistema imaginable que pueda concebirse como un verdadero sistema jurídico. Pongamos esto un poco más en su contexto. Las leyes promulgadas por los legislativos de todo el mundo tienen el rasgo de consistir en series ordenadas de enunciados normalmente denominadas «artículos», o «secciones», o «epígrafes», o algo por el estilo, a menudo con subapartados en su seno, y normalmente con algún sistema de numeración. Dicho de manera general: las leyes son secuencias de enunciados susceptibles de ser entendidas como normativas en su significado, que configuran algún tipo de estructura normativa cuando se leen como una agrupación de conjuntos de enunciados, sobre todo cuando se toman como un todo. Las leyes pretenden promulgarse para establecer nuevas normas de conducta y responsabilidad en el seno de lo que se concibe como un orden jurídico dinámico. El contenido del orden jurídico que las rodea queda modificado por la promulgación de la ley dentro del sistema.

Esto me permite enfocar un poco más de cerca el mencionado principio de que uno no puede basarse en una ley sin decir en qué ley se basa uno. Para decir cómo se basa uno en una ley, hay que especificar qué artículos (qué enunciado o enunciados del texto legal) se consideran relevantes y aplicables a la postura que uno está sosteniendo. Esto vale por igual para las acusaciones penales, los procesos contencioso-administrativos, o los pleitos civiles; el fiscal, o la autoridad administrativa, o el litigante privado deben decirle al tribunal qué fragmentos de la ley —cuáles de sus enunciados numerados- se supone que están en juego.

${ }^{2}$ Véase Soeteman, 1989: Logic in Law, Dordrecht: Kluwer Academic Publishers, sobre la dependencia mutua entre elementos deductivos y no deductivos del razonamiento en el contexto jurídico.

3 Véase Summers y TARUFFO, 1991: «Interpretation and Comparative Analysis», en MACCormicK y SumMERS (eds.), Interpreting Statutes: a Comparative Study, Aldershot: Dartmouth, pp. 461-510, esp. en pp. 490-91, sobre elementos invariablemente presentes en las decisiones judiciales a través de nueve sistemas jurídicos diferentes. 
Permítaseme añadir una idea adicional: también tiene que haber algunas cuestiones de hecho relevantes. Lo que está en juego puede ser una acusación por la comisión de un delito previsto como tal en una ley penal. Puede tratarse de la solicitud de que un acto administrativo sea declarado válido, o nulo, bajo las disposiciones de una ley. $\mathrm{O}$ puede que alguien esté demandando que, a tenor de una determinada ley, esa parte tiene derecho a una determinada pretensión (p.e., a una indemnización por daños) frente a la otra parte. Sea como fuere, el proceso será incoherente, o una farsa, a menos que la parte que plantea una solicitud ante un tribunal presente algunas alegaciones de hecho susceptibles de ser enjuiciadas y admitidas. Por otra parte, es obvio que esas alegaciones de hecho tienen que ser relevantes a la luz de las disposiciones legales citadas por el fiscal o la autoridad administrativa o el litigante privado como fundamento de su petición en el proceso en cuestión.

Quizás nadie ponga esto en duda. Quizás estas observaciones no merezcan más que el reproche de estar insistiendo en lo que es obvio, ya que nadie va a discutir la afirmación trivial que se está haciendo. Tal vez sea así, o tal vez no; pero lo que de verdad merece atención aquí es la idea de qué es lo «relevante». ¿Cuál es el test para eso? ¿Cómo sabemos qué es lo relevante? ¿Cómo ha de plantear uno alegaciones de hecho «relevantes» para ser enjuiciadas por un tribunal en relación con alguna o algunas disposiciones de una ley? La respuesta es obvia, y no particularmente sorprendente. Para descubrir qué es relevante hay que leer la ley.

Tomemos como ejemplo una versión imaginaria y ligeramente esquemática de una ley que podría pertenecer a algún Estado de la Unión Europea, a través de la cual ese Estado transpuso en su Derecho interno las disposiciones de la Directiva Europea sobre Responsabilidad por Productos. Supongamos que la ley nacional dice en su artículo $n$ :

«1. Si un artículo es un producto, y si está en posesión de o siendo usado por un consumidor, y si el consumidor sufre algún daño causado por un defecto del producto, entonces el fabricante del producto quedará obligado a indemnizar al consumidor por el daño sufrido, y esa responsabilidad no estará condicionada a prueba alguna de culpa o negligencia por parte del fabricante». Llamemos a esto «la regla de responsabilidad objetiva».

Podemos imaginar unos apartados adicionales como estos:

«2. Si un consumidor dañado por un producto no es capaz de descubrir la identidad de su fabricante, o si el fabricante es insolvente, el consumidor tendrá derecho a exigir a quien hubiere suministrado el producto la misma indemnización que hubiera podido reclamar del fabricante». Llamemos a esto «la regla de responsabilidad subsidiaria».

«3. Si el daño a un consumidor causado por un producto es atribuible a un defecto intrínseco al diseño del producto, y si el fabricante puede demostrar que la posibilidad de tal daño era imposible de prever en el estado del conocimiento científico disponible para el fabricante en el momento en que el producto fue diseñado, el fabricante quedará exento de la responsabilidad de indemnizar al consumidor a la que se refiere el apartado 1 del presente artículo». Llamemos a esto «la eximente del riesgo de innovación».

«4. Si, al momento en que un consumidor sufre el daño al que se refiere el apartado tercero del presente artículo, el fabricante hubiere tenido conocimiento previo de la posibilidad de que el producto causara el daño, y no hubiere tomado todas las medidas razonables (sobre cuya adopción la carga de la prueba a él le corresponde) para advertir a todos los consumidores del riesgo en cuestión, dicho fabricante incurrirá en la responsabilidad a 
la que se refiere el primer apartado del presente artículo, quedando inaplicable el apartado tercero». Llamemos a esto «la excepción por omision de aviso razonable».

Seguramente resulta obvio que ninguna abogada competente podría, o pensaría que podría, reclamar una indemnización para una persona dañada, basándose en esta ley, a menos que estuviera dispuesta a hacer alegaciones que vinculen las circunstancias particulares de la persona dañada con las categorías correspondientes desplegadas en el texto de dicha ley. Estas categorías son las de persona, daño, consumidor, fabricante, producto, defecto, y causa. Para valerse de esta ley, lo que ha de alegarse es que una persona $\mathrm{C}$, el demandante o reclamante, ha sufrido un daño; que $\mathrm{C}$ era un consumidor que poseía o utilizaba un determinado artículo $\mathrm{P}$ en calidad de consumidor; que la causa del daño fue un defecto en ese artículo; y que el artículo era un producto fabricado por el demandado F, que era, en el sentido de la ley, el fabricante del producto. No hará falta alegar que el fabricante fue negligente. $Y$ si $\mathrm{C}$ no pudiese identificar al fabricante, o bien si este fuese insolvente, entonces, bajo la «regla de responsabilidad subsidiaria», habría que alegar que se da una u otra de estas circunstancias y que el demandado $S$ había suministrado el producto a $\mathrm{C}$.

Entre todas las variedades de Derecho procesal que existen, es difícil imaginar un sistema jurídico que no requiera de alguna manera que el demandante en algún momento plasme tales alegaciones de modo razonablemente conciso por escrito y se las traslade al demandado. A su vez, el demandado tiene que decidir si las admite, o si las rechaza y deja que el demandante intente probarlas en alguna forma de enjuiciamiento de cuestiones de hecho. O bien, por supuesto, en la situación que hemos imaginado, el demandado podría quizás invocar mi artículo $n$ apartado 3, la «eximente del riesgo de innovación». Para ello, F tendría que alegar que el defecto, si lo hay, fue un defecto de diseño y que en el estado del conocimiento científico en el momento del diseño no habría sido posible conocer o haberse precavido contra el riesgo en cuestión. C, a su vez, puede simplemente negar esto y dejar que el demandado pruebe los hechos necesarios para poder acogerse a esta eximente, o bien podría invocar la «excepción de omisión de aviso razonable» del apartado 4. Ello requiere alegar que el defecto había sido descubierto a tiempo pero que no se había dado aviso de modo tal que llegara al conocimiento de C. Por último, F podría replicar que él había tomado todas las medidas razonables para comunicarse con todos los usuarios posibles del producto. Salvo que se alcanzara un acuerdo satisfactorio para ambas partes, el caso iría finalmente a juicio, y el resultado dependería de la cuestión de cuál de las partes pudiera probar, según el estándar de prueba pertinente, los hechos contenidos en sus alegaciones.

Antes he dicho que las posturas iniciales en un caso equivalen a un intento de construir un silogismo jurídico ${ }^{4}$. Es fácil ver por qué. Las leyes típicamente se expresan en términos de universales: «quien sea un consumidor», «quien siendo un consumidor sufra un daño», «siempre que el daño sea causado por un defecto en un producto», «el fabricante del producto que causa el daño quedará obligado sin que se pruebe su culpa a indemnizar al consumidor dañado». De la infinidad de particulares en el mundo,

${ }^{4}$ Véase WALKER, 1951: «The Theory of Relevancy», Juridical Review 63, 1 en p. 3, discutido en MACCoRMICK, 1994: Legal Reasoning and Legal Theory, ed. revisada, Oxford: Clarendon Press, pp. 71-2. Las observaciones de WALKER se dirigen en particular al sistema escocés de alegaciones en casos civiles, pero la idea se puede generalizar. 
quien quiera aplicar una ley tiene que seleccionar un conjunto de particulares que ejemplifiquen los universales (consumidor, daño, causa, producto, fabricante) desplegados en la ley, y tiene que probar hechos y sucesos que demuestren los particulares alegados como ejemplos o casos concretos de los universales.

La forma lógica de esto puede representarse de diversas maneras. La premisa mayor es la ley. Es necesariamente universal en sus términos. Antes presenté esto de una forma muy tosca, como simplemente ligando un conjunto de hechos operativos en bloque con la consecuencia normativa que ha de seguirse de ellos (Si OF, entonces NC). Pero, para desarrollar mi argumento, es mejor dividir las partes de la regla en componentes más refinados que ayudarán a resaltar el carácter lógico de lo que está pasando. Así pues, podemos representar esquemáticamente la disposición legal de la siguiente manera: para todo $c$, para todo $f$ y para todo $p$, si c es un consumidor de productos y si $p$ es un producto, y sif es el fabricante de $p$, y si c sufre un daño y si la causa del daño de $c$ es un defecto en p, entonces festá obligado a indemnizar a c.

Las alegaciones sobre hechos equivalen a un conjunto de premisas menores que necesariamente son particulares, porque es un demandante concreto quien busca una indemnización de un fabricante concreto. De modo que lo que ha de alegarse es que cada uno de los universales de la ley está ejemplificado [instantiated] en el caso particular. Connie es una consumidora, Connie ha sufrido un daño, el daño de Connie fue causado por un defecto en esta cosa, esta cosa es un producto, Paul es el fabricante de esta cosa. La pretensión fundada en estas alegaciones es la conclusión del silogismo: Paul está obligado a compensar a Connie por el daño que ella sufrió por esta causa. Si se abre un juicio, la cuestión clave es demostrar la corrección de esa misma pretensión, y persuadir así al tribunal para que conceda una indemnización por daños equivalente al valor pecuniario atribuido al daño y a sus nocivas consecuencias para Connie. Esto por lo que se refiere a la justificación de pretensiones, o a la justificación de decisiones judiciales sobre ellas, lo mismo da. Asumamos por alguna razón que una determinada ley debe ser obedecida en un cierto territorio. Entonces, mostrar que un determinado caso es de los que ejemplifican los hechos operativos estipulados en términos universales en la ley es mostrar que la consecuencia normativa ligada por la ley a esos hechos operativos debe también ejemplificarse convenientemente. Un fallo del tribunal a tal efecto está por tanto justificado según Derecho.

Presenté una version anterior de esta conferencia como la Dewey Lecture de la Universidad de Minnesota en su edición del año 2000. Cuando viajaba a Minneapolis para pronunciar la conferencia, resultó que la noticia del día fue la sentencia del juez Thomas Penfield Jackson, del Tribunal Federal de Distrito de Washington, D.C., en el caso antimonopolio de Microsoft. Los fundamentos de Derecho declarados por el juez Jackson incluyeron lo siguiente ${ }^{5}$ :

«Los Estados Unidos, diecinueve Estados individuales, y el Distrito de Columbia ("los demandantes") plantean este litisconsorcio ejecutivo civil contra el demandado Microsoft Corporation ("Microsoft") bajo la Ley Sherman Antitrust, 15 U.S.C., arts. 1 y 2. Los demandantes denuncian, en esencia, que Microsoft ha desplegado una campaña ilegal en defensa de su posición de monopolio en el mercado de sistemas operativos diseñados para funcio-

${ }^{5}$ United States v. Microsoft Corp., 87 F. Supp. 2d 30 (D.D.C. 2000) («Conclusions of Law»). 
nar en ordenadores personales ("PCs") compatibles con Intel. Concretamente, los demandantes alegan que Microsoft infringió el art. 2 de la Ley Sherman al embarcarse en una serie de actuaciones excluyentes, anticompetitivas y predatorias para mantener su poder monopolístico. También afirman que Microsoft intentó, aunque sin éxito hasta la fecha, monopolizar el mercado de buscadores de Internet, igualmente en violación del art. 2. Por ultimo, sostienen que ciertas medidas tomadas por Microsoft como parte de su campaña para proteger su poder monopolístico, concretamente la de vincular su buscador a su sistema operativo y la de llegar a acuerdos comerciales en régimen de exclusiva, infringían el art. 1 de la Ley.

A la vista de la declaración de hechos probados («Resultandos») emitida por este tribunal el 5 de noviembre de 1999 y modificada el 21 de diciembre de 1999, así como de la propuesta de fundamentos de Derecho presentada por las partes, de los informes de los coadyuvantes [amici curiae*], y de la argumentación de los letrados sobre ellos, este tribunal concluye que Microsoft mantuvo su poder monopolístico mediante prácticas restrictivas de la competencia, y que intentó monopolizar el mercado de buscadores de Internet, ambas cosas en violación del art. 2. Microsoft también infringió el art. 1 de la Ley Sherman al ligar antijurídicamente su buscador de Web a su sistema operativo».

Los términos de los arts. 1 y 2 de la Ley no se recogen explícitamente aquí, pero se alude a ellos inequívocamente. La argumentación es jurídicamente formalista en su presentación, aunque esté presentada de modo un tanto informal desde el punto de vista de un lógico. Su estructura básica es inconfundible, y es la que estoy describiendo aquí.

Para algunos la utilidad de este ejemplo puede resultar debilitada por el hecho de que la sentencia del juez Jackson fue rápidamente anulada en segunda instancia por el Tribunal Federal de Apelaciones del Distrito de Columbia ${ }^{6}$, debido entre otras cosas a la conducta inadecuada del juez:

«Anulamos el fallo y la condena, porque el juez de primera instancia entabló contactos ex parte no permitidos al conceder entrevistas secretas a algunos medios de comunicación, y realizó numerosos comentarios ofensivos sobre los ejecutivos de Microsoft en declaraciones públicas fuera del Juzgado, dando lugar a una apariencia de parcialidad. Aunque no encontramos pruebas de tendenciosidad efectiva, consideramos que las acciones del juez de instancia contaminaron gravemente las actuaciones ante el Tribunal de Distrito y pusieron en entredicho la integridad del proceso judicial. Nos vemos por tanto obligados a anular el fallo, con efectos devolutivos para que la resolución condenatoria sea reconsiderada, y disponemos que el caso sea reasignado a otro juez en primera instancia».

Esto, sin embargo, lo único que muestra es que los jueces pueden cometer errores de más de un tipo, incluyendo el de no preservar la integridad de las actuaciones judiciales por parcialidad o prejuicio real o aparente ${ }^{7}$. También muestra que una estructu-

"En Derecho norteamericano un «amicus curiae» es una persona que, a petición propia o requerido por el tribunal, sin constituirse en parte del proceso, interviene en el mismo y aporta un «brief» o informe argumentando y pronunciándose sobre el caso, dado que dicha persona tiene un poderoso y legítimo interés en el asunto. En Derecho español son figuras próximas a esta las de la llamada (por la jurisprudencia y la doctrina) «intervención adhesiva simple» en el proceso civil, o la del «coadyuvante» en el contencioso-administrativo. He optado por traducir con esta última palabra por ser más sencilla y expresiva (N. del T.).

${ }^{6}$ United States of America v. Microsoft Corporation US Court of Appeals, DC Circuit (Caso 00-5212, sentenciado el 28 de junio de 2001).

7 Puede compararse con el error de Lord Hoffman por no abstenerse en la apelación del «caso Pinochet», en el que estaba implicada una organización de la cual él era uno de sus patronos (R. v Bow Street Magistrate exp. Pinochet (No 2) [2000] 1 ac 119). 
ra formalmente correcta de una argumentación puede coexistir con la incorrección material en la dirección del caso, o de hecho con algún error argumentativo en el establecimiento de una o varias premisas. Sin embargo, el procedimiento de anulación por parte del Tribunal de Apelaciones presenta básicamente la misma forma, esta vez (es de esperar) sin incorrecciones materiales: si se estima que un juez ha dado apariencia de parcialidad, su sentencia debe ser anulada; este juez dio apariencia de parcialidad; por lo tanto, su sentencia debe ser anulada.

En cualquier caso, la relevancia y aplicabilidad del silogismo me parece muy clara, difícilmente discutible. Pero quizás sea un sinsentido escandaloso después de todo. ¿№ debería a uno preocuparle que esto parezca una revuelta radical contra la lógica de probabilidades y no de certezas de DEWEY $^{8}$, o sea, un regreso absurdo al formalismo y a la jurisprudencia mecánica? En el mejor de los casos, mi defensa del silogismo tal vez diga algo sobre el Derecho legislado, y puede tener sentido para algún género de sistema codificado de tipo continental. Pero es completamente ajena al espíritu del common law. Y de todos modos, ¿qué hay del hecho de que el Derecho es un concepto interpretativo y de que todo el razonamiento jurídico es interpretativo y está impregnado de valores hasta la médula?

Enseguida abordaremos estos problemas. Independientemente de lo que digamos sobre ellos, aquí ya se ha establecido una postura que permite decir un poco más sobre la idea de que el Derecho puede realmente marcar una diferencia. Por ejemplo, la actividad de los agentes profesionales del lobby ante las asambleas legislativas resulta que en realidad para algo se hace. No es sólo una cuestión de triunfos y desastres simbólicos, no sólo se trata de dar gato por liebre a clientes ingenuos que les han contratado o a parlamentarios vanidosos ante quienes actúan, aun cuando siempre existe la posibilidad de que también estas cosas estén en el ambiente. Lo que cambiamos cuando cambiamos el Derecho de un Estado, o de una Unión federal o confederal, son los fundamentos posibles de los argumentos jurídicos, y las pretensiones y decisiones jurídicas que esos argumentos pueden sustentar.

Nuestro imaginario Derecho de Responsabilidad por Productos hace posible que los consumidores interpongan demandas de responsabilidad contra los fabricantes y otros productores pese a la ausencia de toda alegación de culpa, y quizás en ausencia de toda posibilidad de lograr que una alegación de culpa se sostuviera. Si se añade el apartado de «riesgo de innovación», ello permite al fabricante en el caso de productos de nuevo diseño esgrimir una eximente que funcionará, en los casos que cubre, como una posible excepción a la estricta responsabilidad objetiva o sin culpa. Esto no nos dice con certeza o en absoluto cuál será el índice de demandas, o el número de situaciones en las que (si existe) la «eximente de riesgo de innovación» será utilizable o utilizada, ni con qué éxito. Pero la mera posibilidad jurídica de demandas y eximentes y cosas así es algo que afecta a cosas tales como los mercados de seguros o la asunción de riesgos por parte de las empresas de fabricación, etc. No debería sorprendernos nada la creencia manifiestamente extendida de que los cambios en las leyes pueden tener un impacto real en las relaciones económicas y sociales, y de que la dirección del cambio y de su impacto también puede preverse, aunque no sea con exactitud y certeza.

\footnotetext{
${ }^{8}$ DEWEY, «Logical Method and Law», citado en nota 1.
} 


\section{2. ¿EL DERECHO COMO INTERPRETACIÓN?}

Lo de la exactitud y certeza me devuelve a la cuestión del carácter interpretativo del Derecho ${ }^{9}$. Por supuesto que el Derecho no es una ciencia exacta, y por supuesto que la toma de decisiones jurídicas y el razonamiento jurídico justificativo carecen del carácter demostrativo que su reconstrucción en forma silogística parecería atribuirles. ¿Qué explicación puede darse de esto? La respuesta es clara en principio. Obsérvese esto: lo que hasta aquí se ha discutido es el proceso de alegación [pleading], el de erigir una pretensión que depende de que la ley sea aplicable a un caso particular. Pero hay que atender no sólo a la elaboración de la pretensión, sino también a la elaboración de la decisión acerca de la pretensión. ¿Qué tipo de justificación es posible para la decisión de aceptar y hacer ejecutar tal pretensión, o para la decisión de rechazarla? Hasta ahora hemos asumido el presupuesto de que todos los aspectos de la pretensión resultan ser indiscutidos y todos los extremos necesitados de prueba han sido efectivamente probados. Pero eso es lo que nunca puede asumirse de antemano.

Para cada concepto, para cada universal como «consumidor», «fabricante», «producto», «daño», o «causa», tenemos que aportar una ejemplificación particular en el caso que planteamos ${ }^{10}$. Pero cada uno de esos términos es susceptible de interpretación, y esto supone interpretación a la luz de una comprensión del propósito del Derecho, de su adecuación al Derecho que le rodea y de un sentido de justicia apropiado al campo jurídico en cuestión. Puede haber disputas sobre términos y conceptos en su uso general. Por ejemplo, el discurso jurídico abunda en teorías rivales de la causalidad. Puede que la respuesta en un determinado caso dependa de una tesis teórica general de este tipo, y el tribunal tendrá que decidir cuál es la teoría de la causalidad apropiada para interpretar el concepto «causa» tal y como es empleado en esta ley. Siempre es posible que una pretensión pueda ser problematizada como una cuestión general de interpretación de este tipo. Cuando lo es, no puede haber una buena decisión para el caso mientras las visiones rivales sobre la interpretación no hayan sido escuchadas y tomadas en consideración adecuadamente, y no se haya alcanzado y justificado una conclusión.

Si volvemos al caso Microsoft nos encontramos, poco después de los «fundamentos de Derecho» antes citados, con la siguiente elucidación sobre «poder monopolístico»:

«Siendo el elemento umbral de una infracción monopolística del art. 2 la "posesión de poder monopolístico en el mercado relevante", el tribunal tiene que determinar primero las fronteras de la actividad comercial que pueda calificarse de "mercado relevante".

En este caso, los demandantes sostuvieron que el mercado relevante era el de concesión en todo el mundo de licencias de sistemas operativos de PC compatibles con Intel. Si este campo de actividad comercial constituye o no un mercado "cuya monopolización puede ser

\footnotetext{
${ }^{9}$ Por esta idea, la comunidad jurídica en general, y yo mismo en particular, estamos en deuda con la obra de DwORKIN, 1986: Law's Empire, Cambridge, MA: Harvard University Pres, aunque la palabra «interpretativo» [«interpretative»] es preferible por razones etimológicas a la de «interpretivo» [«interpretive»] que usa DWORKIN.

${ }^{10}$ Véase la crítica de White, 1979: «Book Review», 78 Michigan Law Review, pp. 737-42, a mi anterior formulación del presente punto (Legal Reasoning and Legal Theory, cap. 2), en la que ella pone de manifiesto poderosamente el alcance de «ejemplificación de un universal» [«universal instantiation»].
} 
ilegal", depende de si incluye todos los productos "razonablemente intercambiables por los consumidores para el mismo propósito". Véase Rothery Storage and Van Co. v. Atlas Van Lines Inc. ("Dado que la capacidad de los consumidores de recurrir a otros proveedores impide a una empresa subir los precios por encima del nivel competitivo, la definición de "mercado relevante" descansa en la determinación de los sustitutos disponibles" ${ }^{11}$ )».

En su posterior análisis de los detalles del caso, el Juez Jackson declara su aceptación de esta glosa interpretativa sobre la ley en cuanto que proporciona una base sólida para su propia argumentación.

Una posibilidad estrechamente relacionada, similar pero no idéntica, se refiere al modo en que los particulares de un caso se despliegan. Hay un carácter narrativo inevitable en todo intento de captar, no digamos ya de probar, sucesos que ocurrieron en el pasado. Los casos jurídicos muy frecuentemente se refieren a sucesos que ocurrieron antes del litigio relativo a ellos, y de ahí que la tarea de alegar y probar un caso conlleva la construcción de narraciones, así como el uso de narraciones de testigos al reconstruir el caso. Independientemente de cómo quede la historia, de cuál sea su solidez en algunos puntos y su fragilidad en otros, lo cierto es que es bastante probable que al final los particulares sean vistos bajo una luz algo distinta de la de su presentación inicial. Y entonces surge la pregunta: «¿Pero eso realmente cuenta como un ejemplo o caso particular del concepto en cuestión, dado el sentido que atribuimos a este en la ley?».

Supongamos que una diputada del Parlamento Europeo compra un ordenador portátil para utilizarlo en su despacho del Parlamento, pero a veces se lo lleva a casa. Un día está escribiendo unas cartas familiares en ese ordenador en su casa, y de repente el ordenador se incendia, y le quema a ella y se destruyen un montón de datos que necesita urgentemente para su trabajo parlamentario. ¿Cuenta alguno de sus daños, y en su caso cuáles, como daños sufridos por ella en su calidad de consumidora?

En estos problemas de clasificación o calificación (en francés, «qualification» ${ }^{12}$, «caracterización» en la terminología de las normas de conflicto) ponemos en marcha una doble interpretación. Por un lado, analizamos el sentido de la ley para ver si es esta la clase de situación que cae dentro del espíritu de la ley. Por el otro, estamos interpretando la situación como una situación social de un cierto tipo que puede que caiga o no dentro de lo que típicamente consideramos como protección al consumidor. Quizás el ejemplo más célebre de tal «problema de calificación» fue Brown v Board of Education of Topeka ${ }^{13}$, donde el tribunal Warren dictó su célebre sentencia sobre la cuestión de si la enseñanza segregada de los niños negros contaba como «igual trato» a efectos de la «igual protección de las leyes» garantizada por la Decimocuarta Enmienda de la Constitución norteamericana.

Tomando nuestro ejemplo de Microsoft, cabe destacar el siguiente elemento de la sentencia:

${ }^{11}$ Citado en nota 6.

12 Véase Troper, GrZÉGORCZYK y GARDIES, 1991: «Statutory Interpretation in France», en MACCORMICK y SuMmERS (eds.), 1991: Interpreting Statutes: A Comparative Study, Aldershot: Dartmouth, pp. 171-212, en pp. $198-9$.

13 (1954) 347 US 483. 
«Si el demandado con poder monopolístico contrarió conscientemente a sus clientes al hacer sus productos menos atractivos para ellos —o si incurrió en otros costes, tales como grandes desembolsos de capital de desarrollo y pérdida de oportunidades de derivar ingresos de ello-, sin perspectivas de otra compensación que no fuera la de la erección de barreras contra la competencia de empresas igualmente eficientes, el tribunal debe considerar la conducta del demandado como "predatoria"».

Esta parte de la sentencia, leída conjuntamente con los párrafos posteriores, es un caso paradigmático del tipo de argumento sobre el que estoy llamando la atención aquí. Apenas menos relevante es en realidad el resultando del Tribunal Federal de Apelaciones acerca de que las indiscreciones del juez Jackson «contaminaron gravemente las actuaciones ante el Tribunal de Distrito y pusieron en entredicho la integridad del proceso judicial».

Otra variación sobre este tipo de problema surge del uso de los llamados «estándares» en las disposiciones legales. Por ejemplo, la hipotética ley de Responsabilidad por Productos con la que estamos trabajando contiene la disposición que habíamos etiquetado como la «excepción por omisión de aviso razonable», que es una excepción a la «eximente del riesgo de innovación». Para invocar esta última, una empresa demandada tendrá que demostrar que puso toda la diligencia razonable para avisar a los usuarios del producto de un defecto de diseño en él, una vez que ese defecto hubiera llegado al conocimiento de la empresa. En cualquier caso concreto, una vez que las pruebas han llevado a mostrar qué medidas se tomaron para advertir a los consumidores, y cuándo fueron tomadas, y con qué efectos de cara a alertar a los consumidores del riesgo, queda todavía una pregunta: ¿Ese grado de diligencia cuenta como razonable? Esto no es tanto una calificación cuanto una evaluación, pero es de nuevo algo que está inmerso en el razonamiento interpretativo. Por un lado, hay que considerar el propósito de la ley en su conjunto para ver de qué clase de riesgos está la ley tratando, y en qué contexto pone en juego el deber de advertir. Por el otro, hay que considerar la idea general de razonabilidad en el Derecho y el tipo de diligencia comúnmente esperada en una situación como la de un fabricante. Podría perfectamente ser relevante el tipo de producto de que se trate, y lo fácil o difícil que sea contactar con compradores conocidos. Los coches, por ejemplo, no son lo mismo que los alimentos frescos, y estos a su vez son distintos de los fármacos, y los fármacos de los ordenadores, y así sucesivamente.

En todos los tipos de razonamiento interpretativo que estamos considerando, no se trata sólo de que tengamos que llegar a una conclusión interpretativa antes de poder aplicar la ley al caso en cuestión o de concluir que es inaplicable. Ocurre también que esas conclusiones mismas pueden justificarse mediante argumentos y sopesando y balanceando las razones a favor de cada una de las posibilidades interpretativas. Aquí entran en juego argumentos relativos a la consistencia interna del Derecho. También entran en juego argumentos relativos a la coherencia global de la ley a la luz de sus principios subyacentes y a la luz de otros principios fundamentales del ordenamiento jurídico, especialmente los que son más relevantes para el sector del Derecho al que pertenece la ley. Pueden plantearse casos hipotéticos que sugieren la inaceptabilidad de una interpretación y la preferibilidad de sus rivales. Se examinan las implicaciones, para el sistema jurídico y para la vida social, de una u otra decisión interpretativa, y en algunos casos los argumentos abiertamente consecuencialistas pueden ser apropiados. 
De modo que, a fin de cuentas, no es que sea el silogismo jurídico por sí solo lo que determina el resultado del caso. Algunos o todos los términos de la ley tendrán que ser interpretados, y los hechos del caso han de interpretarse y evaluarse para determinar si verdaderamente cuentan, si realmente encajan en la ley. Pueden y deben darse razones a favor de las interpretaciones preferidas que son decisivas en un caso. Dejo para otro lugar el examen de la gran cuestión: «¿Qué tipos de razones son apropiadas para esta tarea?». Baste concluir aquí que las razones a favor de una determinada lectura del silogismo son, cabe decir, las verdaderas razones del caso. Esas razones corresponden a una lógica de probabilidades, no de certezas, así que esa es al final la verdadera lógica del asunto.

¿Por qué insistir entonces en el silogismo? La respuesta debería ser obvia: el silogismo es lo que proporciona el marco dentro del cual los otros argumentos cobran sentido como argumentos jurídicos. Volvemos a la cuestión acerca de qué podría contar como aplicación de una ley. Volvemos al asunto de un procedimiento concebible para plantear una argumentación con vistas a la implementación de una ley. Eso tiene su propia lógica intrínseca, dentro de la cual es claro por qué las tesis y argumentos interpretativos tienen una relevancia real como argumentos jurídicos. Por otra parte, esto nos ayuda a recordar por qué es tan importante para un abogado ser meticuloso al examinar cada uno de los universales o conceptos contenidos en una ley, y al determinar su ordenación relevante y su mutua interacción o relaciones de prioridad y subordinación. Los casos se ganan o se pierden mediante un meticuloso cuidado - o su omisión- a la hora de detectar todos los conceptos que cuentan y de examinar rigurosamente, respecto de cada uno, qué particulares contarán como un caso concreto de ese concepto ${ }^{14}$. Por supuesto, esto no significa que sea necesario, ni siquiera lo mejor, exponer los argumentos jurídicos reales en forma rigurosamente silogística. Cómo presentar la argumentación es algo que corresponde a la retórica más que a la lógica; pero la retórica más eficaz probablemente sea la que descansa en una comprensión clara de la lógica implícita del proceso.

En resumen, si consideramos que el silogismo jurídico exhibe el marco de todo razonamiento jurídico que suponga la aplicación del Derecho, hay un número limitado de maneras en que pueden surgir problemas cuya resolución requiera razonamientos en principio no deductivos, o sea, retóricos o persuasivos. Volviendo, por razones de simplicidad, a la fórmula esquemática «Si $O F$, entonces $N C »$, las cuatro maneras siguientes agotan las posibilidades de desafíos que pueden surgir en cualquier caso discutido:

1. No se ha probado (en la medida del estándar de prueba requerido) que haya existido ningún caso particular de «OF» tal y como había sido alegado en la acusación o en la demanda; teniendo en cuenta todos los medios de prueba relevantes y admisibles, incluida cualquier prueba de descargo propuesta por la defensa. (Podemos llamar a esto un «problema de prueba»).

2. Lo que se ha alegado, haya sido o no probado, no se caracteriza adecuadamente como un caso concreto de «OF» en el sentido ajustado a Derecho. (Podemos llamar a esto un «problema de calificación», o de «caracterización», o de «clasificación»). Cuan-

${ }^{14}$ Véase AlEXY, 1989: Theory of Legal Argumentation, trad. inglesa de R. ADLER y N. MACCORMICK, Oxford: Clarendon Press, en pp. 222-30. 
do «OF» es o incluye una expresión valorativa o «estándar», como por ejemplo el de «razonable», «justo», «equitativo», o similares, y la cuestión es si la conducta (etc.) impugnada fue realmente «razonable», «justa», «equitativa», o similar, es mejor considerar el problema relevante como un problema de «valoración».

3. El caso, tal y como ha sido planteado, depende de leer la regla admitida «si $O F$, entonces $N C »$ según una determinada interpretación de «OF», o de «NC», o de ambos; pero esta es una mala interpretación, y hay en realidad una interpretación jurídicamente más acceptable según la cual la parte que se defiende debe ser absuelta de la acusación o demanda presentada contra ella. (Podemos llamar a esto un «problema de interpretación»).

4. El éxito de la demanda o acusación depende de leer los materiales jurídicos autoritativos como si generaran una regla «Si $O F$, entonces $N C »$ tal, que las alegaciones de culpabilidad penal o de responsabilidad civil son relevantes dados los hechos alegados, o incluso los hechos probados; pero ninguna norma así puede leerse adecuadamente a partir de los materiales aducidos como una razonable concretización de ellos o determinación desde ellos. (Podemos llamar a esto un «problema de relevancia». Expuesto así, es un tipo de problema que surge principalmente en los sistemas de common law, o en partes no codificadas de otros sistemas jurídicos, como el Derecho administrativo francés, desarrollado a través de la jurisprudencia del Conseil D’Etat).

\section{3. ¿EL COMMON LAW ES DIFERENTE?}

Para finalizar, abordo la última objeción. Ésta se refiere al especial carácter del common law. Los silogismos, se dice, están muy bien para las leyes y códigos. Pero el common law es diferente. El common law versa sobre casos y analogías, sobre emparejar pautas a través de narrativas similares pero sutilmente diferentes. La idea de fondo es tratar de manera semejante los casos semejantes, y diferente los casos diferentes; la habilidad del abogado radica en desarrollar la semejanza relevante y esquivar la diferencia decisiva. Todo esto es cierto, aunque no hay que olvidar que en los sistemas de common law también hay leyes. Hoy en día, los diversos sectores del Derecho en su mayoría están estructurados mediante leyes, o destacan en ellos importantes leyes reformadoras; y esto ocurre en todas las ramas del Derecho, en los sistemas de common law tanto como en sistemas mixtos ${ }^{15}$ o en los puramente «de Derecho civil». Los escasos pasajes del caso Microsoft antes citados, sin ir más lejos, refuerzan este punto. De modo que será un poco anómalo que lo que cuente como un caso bien argumentado difiera radicalmente dependiendo de que esté o no en juego una ley. No obstante, si las cosas son así, son así, y entonces uno simplemente debe integrar la anomalía en el seno de su visión global.

Yo creo sin embargo que, como de costumbre, las diferencias se exageran. En la mayoría de los sistemas de common law, y también en los sistemas mixtos, buena parte de los elementos básicos del Derecho penal, así como el Derecho de obligaciones, el

${ }^{15}$ Los sistemas mixtos son los que se derivan en parte del (originariamente romano) Derecho civil y en parte del common law angloamericano, p. e., el Derecho escocés, el de Sudáfrica, el Derecho de Luisiana o el de Ceilán. Véase Zimmermann, ReID y Visser (eds.), 2005: Mixed Legal Systems in Comparative Perspective: Property and Obligations in Scotland and South Africa, Oxford: Oxford University Press. 
de contratos y el de daños civiles [torts], y otros sectores relacionados con ellos, todavía se basan en casos judiciales y en comentarios doctrinales más que en leyes. Lo extraño sería que en estos campos la gente pudiese confiar menos que en otros en el Derecho como un marco de reglas razonablemente predecibles para guiar sus vidas. Dado que el Derecho de obligaciones está en el centro mismo de la vida comercial y de negocios, el problema sería grave. Pero no parece que exista. De hecho, no existe.

La clave acerca de los sistemas de common law es que ellos tratan los precedentes judiciales como «fuentes del Derecho». Esto significa que las reglas generales de conducta y de responsabilidad se supone que están implícitas en los casos judiciales, envueltas en las argumentaciones redactadas por los jueces al motivar sus sentencias. Los libros de texto y los comentarios doctrinales se escriben sobre la base de que una afirmación sobre el Derecho puede estar suficientemente sustentada citando una sentencia que sea una «autoridad» sobre ese punto, aunque puede ser discutible si la proposición jurídica del comentarista capta con exactitud la verdadera ratio decidendi de la sentencia citada. De todas formas, las proposiciones de la doctrina científica de una cierta sustancia y generalidad normalmente se construyen mediante la cita de y referencia a varias sentencias, quizás la de un caso paradigmático («leading case») y varios otros casos satélite que explican e interpretan más a fondo el caso paradigmático. Si esto es o no una manera fiable de leer precedentes judiciales es una cuestión que abordaré en otro momento.

Baste aquí con negar que la jurisprudencia de common law pueda concebirse como un ámbito jurídico carente de reglas. El problema no es ese. Lo que ocurre es más bien que las reglas se exponen mediante una interpretación de los casos, y de ahí que prácticamente cualquier formulación puede ser desafiada invocando una interpretación rival del mismo material. El mecanismo de la legislación proporciona a la comunidad de usuarios del Derecho un texto dotado de autoridad para guiar y estructurar la deliberación, conteniendo el texto mismo normas explícitas de conducta y de responsabilidad. Por el contrario, el common law como cuerpo de Derecho jurisprudencial no tiene tales normas explícitas formuladas en sus textos autoritativos, los repertorios de sentencias. Pero sí tiene normas implícitas; si no las tuviera, ni siquiera sería un tipo de Derecho.

Soy muy consciente de que, dirigiéndome a un auditorio de jueces y juristas de países hispanoparlantes, quizás sólo estoy diciéndoles cosas que a ustedes ya les parecen obvias. Pero es que hay un gran debate hoy en día acerca de si existe un radical abismo entre el pensamiento de common law y el de Derecho civil, especialmente en materia de los elementos básicos de la argumentación. Puede por tanto que a ustedes les agrade mi conclusión de que es mucho más lo que tenemos en común que lo que nos diferencia.

(Traducción de Juan Antonio Pérez Lledó) 